\title{
Public Demand for Social Investment: New Supporting Coalitions for Welfare State Reform in Western Europe?
}

\author{
Julian L. Garritzmann, Marius R. Busemeyer and Erik Neimanns
}

\begin{abstract}
Social investment has recently received much attention among policy-makers and welfare state scholars, but the existing literature remains focused on policy-making on the macro-level. We expand this perspective by studying public opinion towards social investment compared to other welfare policies, exploiting new public opinion data from eight European countries. We identify three latent dimensions of welfare state preferences: "social investment", "passive transfers", and "workfare" policies. We find that social investment is far more popular compared to the other two. Furthermore, we identify distinct supporting groups: Passive transfer policies are most supported by lowincome, low-educated people, by individuals leaning towards traditional social values and by those subscribing to left-wing economic attitudes. Social investment policies are supported by a broad coalition of individuals with higher educational backgrounds and left-libertarian views from all economic strata. Workfare policies are most popular with high-income individuals and those subscribing to economically conservative and traditional authoritarian values.
\end{abstract}

KEYWORDS Multidimensional policy preferences, public opinion, social compensation, social investment, welfare state attitudes, welfare state reform 


\section{Introduction}

The topic of social investment has recently received much attention among policymakers and welfare state scholars (Bengtsson et al. 2017; Bonoli 2007; Esping-Andersen 2002; Morel et al. 2012; see Hemerijck (2018) in this collection). While there are many different definitions and conceptions of the social investment model in this literature, the core idea of this rising "paradigm" (Hemerijck 2015) is to transform contemporary welfare states from more passive, transfer-oriented institutional regimes towards systems centered on the development of human capital and skills at different stages of the life-course from early childhood education via schooling up to post-secondary education and lifelong learning. Social investment policies aim at "creating, mobilizing, and preserving" skills (Garritzmann et al. 2017: 36ff.; Busemeyer et al. 2018). Even though the literature is increasingly paying more attention to the politics of reform, the bulk of existing literature focuses on the role of collective actors such as parties, unions, and employer associations in the development of social investment policies. In contrast, we hardly have any knowledge on what citizens think about social investment (we discuss exceptions below), also because of a lack of survey data on this issue so far.

This paper addresses this significant research gap by analyzing public opinion towards social investment policies. We pose and answer three research questions: First, do citizens have coherent preferences towards various policies associated with the social investment model (e.g., childcare, active labor market policies (ALMPs), or higher education) and do these preferences differ systematically from those towards compensatory policies? Second, how extensive is popular support for social investment compared to demand for compensatory social transfer policies? And finally, what are the individual-level determinants of people's preferences towards social investment, i.e. are the supporting coalitions similar to those of more traditional welfare policies? 
Empirically, we study public opinion towards social investments using a new representative survey recently conducted in eight European countries: the INVEDUC survey (Busemeyer et al. 2017). As the existing comparative social surveys (e.g., ESS, ISSP, Eurobarometer) hardly include questions on social investment, the advantage of the INVEDUC survey is that it for the first time allows studying people's social investment preferences empirically (but see Fossati and Häusermann (2014) analyzing Swiss data).

We report three core findings: First, principal component factor analyses reveal that respondents' welfare policy preferences indeed cluster along two dimensions, a social investment and a social compensation dimension. In other words, citizens hold rather coherent preferences towards social investment in general. The partial exception is one form of ALMPs, namely "workfare" (King 1995) or "incentive reinforcement" (Bonoli 2010), which forms a distinct, third dimension. Second, a comparison between support for social investment and social compensation policies shows that social investments are much more popular among the European public than passive transfer-oriented policies. Finally, multivariate regressions show that the supporting groups for social investment indeed vary in important ways from those of more traditional welfare policies (see also Häusermann (2018) in this collection). Overall, our paper seeks to contribute to welfare state research and public policy scholarship more generally by offering the first comparative empirical analysis of public opinion on social investment.

\section{Public opinion towards social investment: theoretical perspectives}

The literature on the politics of social investment has so far focused on causes and effects of (specific) social investment policies on the macro-level (Bonoli 2007, 2013; Esping-Andersen 2002; Garritzmann et al. 2017; Hemerijck 2013; Morel et al. 2012; cf. 
also this collection's introduction: Busemeyer et al. (2018)). In contrast, citizens' preferences on social investments have received much less attention.

There is a significant amount of scholarship on individual social investment policies, but they have usually been analyzed separately from other policies. For instance, a few studies have analyzed attitudes towards early childhood education and childcare (ECEC) (e.g. Henderson et al. 1995; Goerres and Tepe 2010; Mischke 2014; Busemeyer and Neimanns 2017), finding high popular support for the expansion of ECEC, but also some variation within and across countries. Individual preferences are largely determined by materialist self-interest related to variables such as income, educational background, and age, as well as by ideological predispositions. Similar findings have been obtained in studies on attitudes towards education policy (Ansell 2010; Busemeyer 2012; Busemeyer and Garritzmann 2017a; Garritzmann 2015, 2016). Still others analyzed preferences towards active labor market policies (ALMPs). For example, Kananen et al. (2006) used cross-sectional Eurobarometer data, finding that respondents' labor market situation affects their preferences, while income hardly matters. Rueda (2005) investigated preferences towards active and passive labor market policies, studying differences between labor market insiders and outsiders.

Yet, even though there is a significant amount of research on individual social investment policies, there is hardly any work on how these are related and whether they are sufficiently coherent to allow identifying distinct and different supporting coalitions for the social investment vs. the transfer-oriented welfare state model. A noteworthy exception is Fossati and Häusermann's (2014) analysis of Swiss survey data. Their factor analyses show that Swiss citizens' welfare policy preferences are two-dimensional, as preferences towards social compensation and social investment clearly form distinct clusters, and that these preferences are good predictors of voting behavior. The few 
existing studies on social investment attitudes for a broader set of countries (Häusermann and Kriesi 2015; Häusermann et al. 2015) provide first comparative insights, but suffer from shortcomings in the existing comparative social surveys (ESS, ISSP, Eurobarometer), which we discuss below.

Inspired by this literature, our first research question is whether people indeed have coherent preferences towards social investment policies and whether these differ systematically from attitudes towards compensatory social policies. There are good theoretical reasons why this should be the case. First, the social investment literature (Hemerijck (2018) in this collection) emphasizes the importance of complementarities between different social investment policies. These complementarities arise from the fact that the social investment strategy aims at promoting the creation, mobilization, and preservation of human skills across different stages of the life-cycle from early childhood education to lifelong learning (Garritzmann et al. 2017). Second, as we substantiate below, the beneficiary groups supporting social investment are different from those of social compensation, which could eventually encourage parties to mobilize different supporting coalitions for their policies. Young, well-educated middle-class parents, for example, benefit not only from the expansion of childcare facilities, but also from more investment in education and labor market training. Vice versa, the primary beneficiaries of social transfers - the poor, the ill, and the long-term unemployed might be less (or not at all) interested in the expansion of social investment. On a more conceptual level, proponents of the social investment perspective point out that it represents a distinct justification for government involvement, which is complementary to the classical social insurance and redistributive functions of the welfare state (Barr 2012). In comparison to the latter two, social investment policies are geared towards 
preventing the emergence of social risks in a pro-active manner, whereas typical social insurance and redistributive policies compensate ex post.

That said, the concept of the social investment state remains elusive and ambivalent in many ways (see Busemeyer et al. (2018) in this collection). In the political realm, it has been used by different political actors for different purposes, which was possible due to the ambiguity of the concept. The "Third way" approach (Giddens 1998), partly implemented by the Blair and Schröder governments, might be considered as precursor to the social investment debate of the 2000s. However, these earlier policies often contained strong elements of "incentive reinforcement" (Bonoli 2010) or "workfare" (King 1995), promoting new kinds of ALMPs that strongly and often negatively incentivize the unemployed to get back into employment rather than engaging in retraining. In contrast, this workfare approach had not been a strong component of the universalist welfare model in Scandinavia, which is upheld as a role model of the social investment state among supporters because of its early expansion of social services complementing generous transfer schemes.

Rather than addressing - let alone solving - these ambiguities on the theoretical level, we adopt an empirical approach in this paper. We are interested to what extent attitudes towards different social investment policies correlate with each other. We want to understand whether the public identifies distinct "policy packages" and whether these are different from the packages promoted by policy-makers of different stripes. For instance, even though workfare-style policies are often discussed in the context of activation policies by policy-makers, individual support for these policies might not be associated with support for other social investment policies because of their emphasis on negative incentives. Also, depending on the particular political context there might be 
some cross-national variation in how policy packages are reflected on the level of public opinion. In sum, we expect:

Citizens' preferences towards different social investment policies cluster along a distinct dimension, whereas attitudes for social transfer policies cluster along a second dimension (Hypothesis 1).

Our second research question is - assuming two-dimensional preferences for now - how popular social investment is vis-à-vis compensatory policies. There are empirical indications that individual social investment policies such as education and childcare are popular, but there is no solid evidence on the popularity of the social investment model in its entirety (but see Busemeyer et al. 2017; Busemeyer and Garritzmann 2017b). Still, it is plausible to expect that social investment policies are highly popular (see also Bonoli 2013), because they create benefits for large parts of the electorate, in particular the well-educated (and politically active) middle class. The social investment model might also receive considerable political support, because it is - partly also because of its ambiguity - appealing to people with different ideological predispositions, taking up a 'middle-ground' between state- and market-based solutions. In other words, social investment could be a valence issue, which is difficult to oppose politically. Thus, we hypothesize:

Social investment is highly popular among the European public, particularly vis-à-vis compensatory social policies (Hypothesis 2).

Our third research question regards the determinants of people's preferences. We are particularly interested in whether and how the supporting coalitions of social investment policies differ from those of compensatory policies (cf. also Beramendi et al. (2015) for this relationship on the macro-level). We argue that while preferences 
towards social investment and towards compensation are related to a certain degree, they differ in several important respects.

First, we expect that the traditional 'class conflict' identified for compensatory social policies is less important when it comes to social investment. The main reason is that whereas compensatory social policies are often strongly redistributive, the redistributive effects of social investment policies are much more complex as these often benefit the wealthier middle classes (see Bonoli and Liechti (2018) and Pavolini and Van Lancker (2018) in this collection). Thus, we expect that income is an important (negative) determinant of respondents' preferences towards compensatory policies, but not so for social investment. Second, we expect the effect of age to be different. The bulk of social transfer spending (particularly pensions) benefits the elderly, whereas social investments are geared towards the young: children, young adults, and parents. Hence, age should have a positive effect on respondents' compensation policy preferences, but a negative effect on their support for social investment (Busemeyer et al. 2009).

The third factor we emphasize is the role of ideological positions. In the literature on welfare state preferences it is common to measure respondents' position on a unidimensional left-right scale as a proxy for their underlying political preferences. However, a related literature on political behavior, which tends to be neglected in welfare state research, argues that the ideological space is two-dimensional, distinguishing an "economic" and a "social" left-right dimension (for many: Häusermann and Kriesi 2015; Hooghe et al. 2002; Kitschelt 1994). The economic dimension concerns orientations towards the state-market relationship with people on the left supporting a strong role of the state and people on the right supporting market solutions. The social dimension relates to new political issues that have emerged during the post-materialist revolution since the 1970s. This dimension ranges from "Green/alternative/libertarian" 
(GAL) values, on the one hand, to "traditional/authoritarian/nationalist" (TAN) orientations, on the other. We find this differentiation helpful because it has important implications for the study of social investment and social compensation policies (cf. also Beramendi et al. 2015; Häusermann and Kriesi 2015).

We hypothesize a positive association between a left-wing position on the economic dimension and support for both compensatory and social investment policies, because both are essentially public policy programs. However, the association should be stronger for compensatory policies, because these are more aligned with the classical redistributive left-right conflict, as argued above. Regarding the GAL-TAN dimen, we expect significant differences between compensatory and social investment policies: Respondents with GAL-views should favor social investments but be relatively opposed to compensation policies, because they are more in favor of equality of opportunities, gender equality, and socio-economic upward mobility (all of which the social investment paradigm seeks to achieve). In contrast, compensatory policies are often built upon a logic of status maintenance and were established in a time when the male-breadwinner model was dominant. Thus, egalitarian, post-materialist individuals can be assumed to support future-oriented social investments, but to be relatively opposed to traditional welfare policies. Vice versa, citizens with more TAN-views should favor social transfers, but oppose social investments.

Taken together, we expect:

The determinants of respondents' preferences towards social compensation and social investment differ in important ways. Social investment and social compensation have very distinct supporting coalitions (Hypothesis 3) (see also contribution Häusermann (2018) in this collection). 


\section{Empirical analysis}

\section{Data}

In order to test our arguments, we need country-comparative data on people's preferences on social investment policies and compensatory welfare policies. Unfortunately, the existing international comparative surveys (e.g. ESS, ISSP, or Eurobarometer) do not include questions that allow operationalizing our dependent variable in a valid way. ${ }^{\mathrm{i}}$

Therefore, we conducted an original representative survey in eight Western European countries: the "Investing in Education in Europe" (INVEDUC) survey (Busemeyer et al. 2017). The eight countries were chosen to cover the variety of welfare state regime traditions across Western Europe to increase the generalizability of the results: Denmark, Sweden, Germany, France, Spain, Italy, the UK and Ireland. The fieldwork was conducted by a professional survey company in April-May 2014, following a set of pretests in the countries. Interviews were conducted by native speakers, using computer-assisted telephone interviewing (CATI) techniques. The total number of observations is 8,905 with about 1,000 to 1,500 cases per country, depending on population size. The average response rate was 27 percent, which is satisfactory for this kind of surveys (see Busemeyer et al. (2017) for details). In the Supplementary Material we present further information on the response rates by country (Table A.1) and summary statistics of our variables (Table A.2).

\section{Operationalization of the dependent variables}

In order to study respondents' attitudes towards social investment policies, we confronted respondents with a number of potential welfare state policy reforms, which the governments in the respective countries might pursue. These reform proposals were 
inspired by policy instruments discussed in the literature on social investment and welfare state reform (Bonoli 2013; Hemerijck 2013; Morel et al. 2012). One of the advantages of our survey is that we do not have to rely on proxies such as people's preferences towards different kinds of public spending (the common practice in other surveys) to understand their policy preferences (cf. Fossati and Häusermann 2014). Instead, we have much more direct, realistic, and concrete measures of respondents' support for social investment and other welfare policies. More specifically, respondents were asked:

“Governments and political leaders like to propose new policy reforms in order to address important social issues. Please indicate whether you would strongly agree, agree, neither agree nor disagree, disagree or strongly disagree with the following reform proposals:

1. Giving the unemployed more time and opportunities to improve their qualification before they are required to accept a job.

2. Expanding access to early childhood education and improving its quality.

3. Investing more money in university education and research at universities.

4. Forcing unemployed to accept a job quickly, even if it is not as good as their previous job.

5. Increasing old age pensions to a higher degree than wages.

6. Lowering the statutory retirement age and facilitating early retirement." ii

In administering the survey, the order of items was randomized to avoid spurious relations. We designed the first three items to capture different key aspects of the social investment paradigm: The first item alludes to ALMPs that place emphasis on (re)training in order to improve the individuals' job perspectives rather than their quick reintegration into the labor market - "upskilling" in Bonoli's (2010) terms. Upskilling is a 
decisive part of the social investment agenda (Bonoli 2010) and has become a widely used policy tool in many European countries. The second item proposes the expansion of childcare (in terms of access and quality), which also is a core component of investment-oriented social policy reforms (Esping-Andersen 2002). The third item proposes expanding investments in universities and research, i.e. forms of human capital that are more relevant in later stages of the life-course with a more direct connection to the labor market (Garritzmann 2016). The first three items thus cover key aspects of the social investment approach. Even though these items all relate to the formation of human skills, they do not simply capture preferences for education policies as they refer to different policies with potentially distinct supporters (the unemployed in the first case, young families in the second, and students and researchers in the third). The fourth item also follows an activation-logic, but refers to the notion of "workfare" policies (King 1995), i.e. ALMPs that set incentives to force unemployed persons back into the labor market. Bonoli (2010) termed these kinds of ALMPs "incentive reinforcements": they have a strong employment-orientation, but lack a social investment component. We are interested in how respondents' attitudes towards this policy relate to their attitudes towards the other policies. Finally, the fifth and the sixth items capture support for more traditional, transfer-oriented social policy reforms. The fifth item proposes to increase pensions more than wages, i.e. to shift resources to oldage pensions above and beyond what would be expected on the background of general wage increases. The sixth proposal is to allow individuals to retire earlier by lowering the statutory retirement age and expanding opportunities for early retirement. These aspects thus focus on social transfer policies and - more importantly - do not contain any social investment aspects.

Admittedly, as we study two policy reforms in the area of pensions, we can only make 
limited claims about passive transfer policy preferences in general. Space constraints in the survey prevented us from including a larger set of social transfer policies. Yet, we chose to focus on pensions, because compared to other social transfers, which are more redistributive in nature, pensions are likely to be supported by larger parts of the population. Hence, measuring support for social investment policies relative to the "high bench-mark" of equally popular pension policies is a conservative test for the general popularity of the former relative to the latter. Furthermore, we conducted an additional factor analysis of preferences for public spending using a different question from the survey. This allows us to compare preferences for spending on three different passive transfer and four different education policy fields (Supplementary Material, Table A.6). These comparisons confirm the existence of two different latent dimensions of welfare state (spending) preferences, as support for more pension spending is highly correlated with support for additional spending on unemployment benefits and health care, but not with support for education spending.

\section{Findings: The multidimensionality of welfare policy preferences}

Addressing the first research question, we performed a principal component factor analysis in order to ascertain whether our presumed classification of policy reforms is

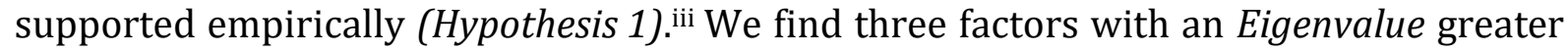
than 1 , which is commonly used as a cut-off point for identifying factors. Table 1 displays the Eigenvalues and the rotated factor loadings. The results clearly reveal that citizens' welfare policy preferences cluster along three dimensions. The factor loadings indicate how strongly the individual variables/items correlate with the respective factor. The analysis shows that - as expected - respondents' preferences towards labor market training, expansion of early childcare, and higher education policies are strongly 
associated. They load on the same factor, which we label as a latent "social investment" dimension. Secondly, preferences towards pension increases and early retirement strongly load on a second factor, which we label "passive transfers". Finally, we identify a third factor ("workfare"), which is strongly associated with the "workfare" proposal, as well as - negatively - with the "upskilling" proposal. This shows that the supporters of the positively activating social investment approach are different from the ones supporting negative incentive structures in labor market policies. In sum, the factor analysis shows that - as hypothesized - respondents have rather coherent preferences towards social investments on the one hand and transfer-oriented consumption policies on the other.

Country-specific factor analyses (see Table A.3 in the Supplementary Material) show that this finding does not only hold for the pooled sample, but also for individual countries. The partial exception to this pattern is the third "workfare"-dimension, where we detect some cross-country variation. In Denmark and the UK, this item loads negatively on the social investment dimension; in Sweden, it is correlated with the items about passive transfers.iv These findings suggest that in countries with a relatively long tradition of social investment and active labor market policies (Hemerijck 2013), citizens understand workfare more as a policy in conflict with more generous approaches to social investment. In line with this, Ireland differs from the UK in that respect. The Swedish case is indicative of a situation where proponents of the social investment model are pitted against supporters of the traditional welfare state model, which in this case includes support for higher social transfers as well as a tighter stance on incentive reinforcement (see also the next section on support levels by country).

Table 1: Rotated factor loadings and Eigenvalues after principal-component factor 
analysis, pooled sample.

\begin{tabular}{l|c|c|c} 
& Factor 1: & Factor 2: & Factor 3: \\
Item & "Social investment" & "Passive transfers" & "Workfare" \\
\hline Labor market training & $\mathbf{0 . 4 1 7 9}$ & 0.1502 & $\mathbf{- 0 . 5 9 2 2}$ \\
Expand early childcare & $\mathbf{0 . 7 6 5 7}$ & 0.0799 & 0.0796 \\
Universities and research & $\mathbf{0 . 7 6 2 3}$ & 0.0094 & -0.0662 \\
Accept job quickly & 0.0808 & 0.0257 & $\mathbf{0 . 8 8 0 7}$ \\
Pension increase & 0.0828 & $\mathbf{0 . 7 8 9 1}$ & 0.1015 \\
Early retirement & 0.0111 & $\mathbf{0 . 7 6 6 0}$ & -0.1424 \\
\hline Eigenvalues & 1.5900 & 1.1092 & 1.0631 \\
& & &
\end{tabular}


Figure 1: Share of respondents supporting social investment, passive transfers, and workfare policy reforms across countries.

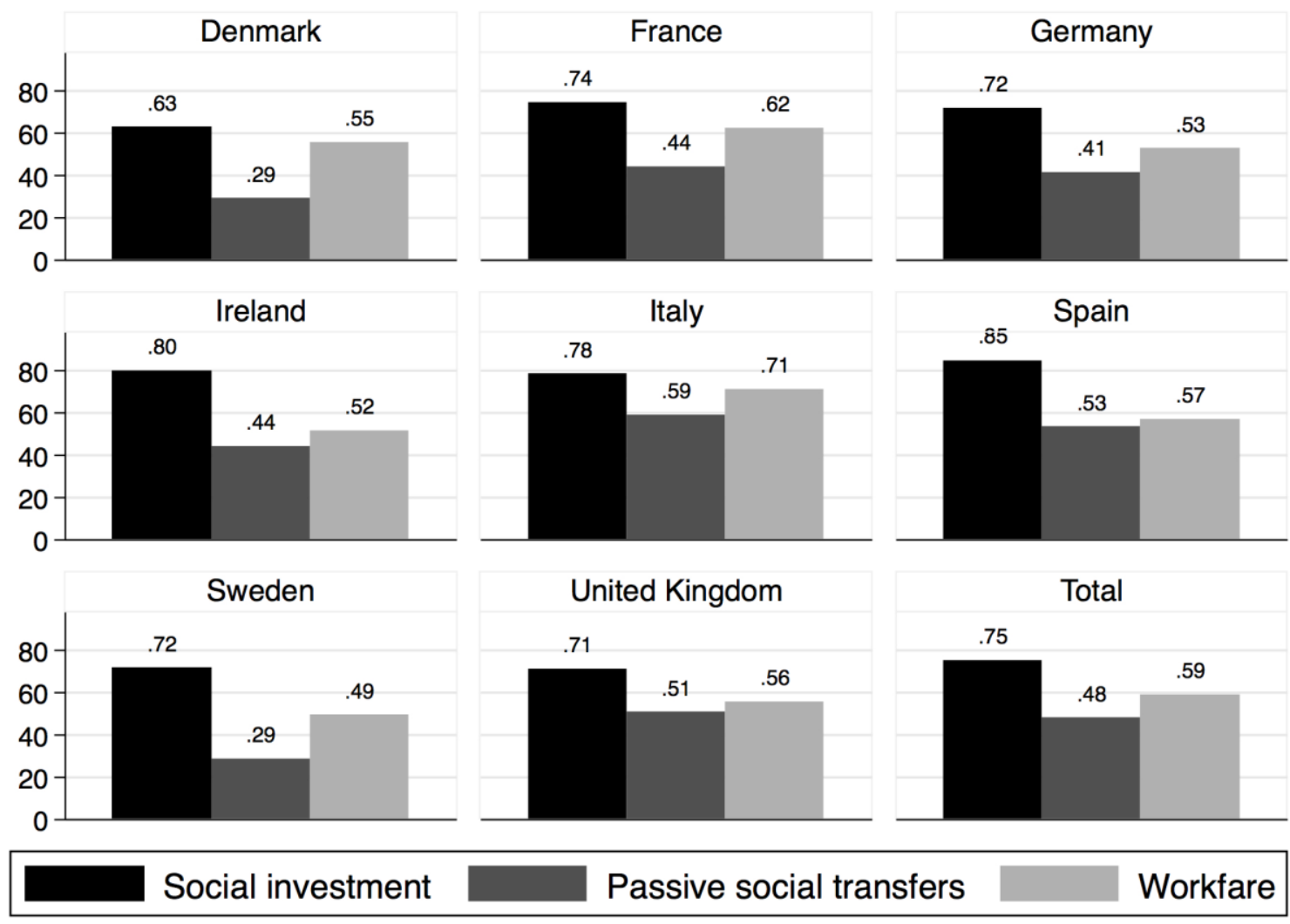

\section{How popular is social investment?}

Our second research question regards the overall popularity of the social investment model (Hypothesis 2). Figure 1 displays support levels for social investment, passive transfers, and workfare policies (survey weights are applied, cf. Busemeyer et al. 2017 for details). It shows the share of respondents who "agree" or "strongly agree" with the respective reforms in each dimension. The figure clearly shows that in all countries expanding social investment is the most popular reform proposal. In the pooled sample about 75 percent of respondent (strongly) agree with these reforms, whereas policy reforms aimed at expanding passive transfers receive much less support (48 percent). Interestingly, reforms to strengthen (negative) incentives for unemployed persons to 
accept jobs actually receives higher levels of support (59 percent) than expanding passive transfer policies. Figure 1 reveals some variation across countries, but overall we observe the same pattern: We find the highest popular support for reforms that expand social investment and the lowest support for expanding social transfers; workfare policies take an intermediate position.

The general popularity of social investment policies is underscored by the fact that even where social investment policies are already well-established (e.g., Denmark and Sweden), citizens are much more in favor of further expanding social investment policies than supporting policy reforms that would increase the generosity of transfers. This relative popularity of social investment appears to reflect the strong expected benefits associated with social investment rather than to represent a simple catch-up process towards the levels of established passive transfers.

\section{Determinants of multidimensional welfare policy preferences}

Finally, our third research question focuses on the determinants of respondents' preferences (Hypothesis 3). As explained above, the goal is to identify potential differences in patterns of support for these different policy approaches. The dependent variables are the three factors identified above. More specifically, we use the predicted values of the rotated factor scores (based on the regression method) for each of the three factors identified in the first part of the empirical analysis. Since the factor analysis transforms the initial variables coded in a five-point scale into a continuous variable with a mean of zero and a standard deviation of 1, we apply OLS regressions. In order to take into account the multi-level nature of the data (individuals nested within countries), we include country dummies and calculate country-clustered robust

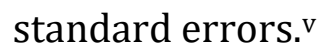


We include several independent variables in the analysis. First, educational background, measured as respondents' highest achieved educational degree from basic to tertiary higher education. Second, respondents' net monthly household income (using individual net income yields the same results), given in county-specific income quintiles. Third, gender (female = "1") and, fourth, whether the respondent has small children living in his/her household (small children is here defined as children below the age of 10, since this is the age when children usually finish primary school). Fifth, age categories are included to test for non-linear age effects (robustness tests indeed reveal that this is the preferred specification). We use those aged 30-39 as the reference category, because they are in their prime working-age and should have the most coherent preferences in comparison to the other age-groups. Those aged 60 and above are further separated into a retired and a non-retired group to allow assessing whether retirement status has an influence on preferences independent of age. Finally, we include two variables measuring the two-dimensional left-right positions laid out above. Both of these scales are derived from a factor analysis of responses to a set of items asked in the survey (see the Supplementary Material for details). Higher values on the economic left-right scale indicate support for a strong role of the market. Higher values on the social values scale imply a more positive orientation towards TAN-values.

Figure 2 graphically shows our regression results by plotting point estimates and confidence bands (the full models are available in Table A.4, Models 1-3 in the Supplementary Material). ${ }^{\text {vi }}$ Most importantly, the analysis reveals clear differences in the determinants of public support across these different models, which indicates that in line with our expectations - the composition of groups supporting these policy reform proposals does vary. First of all, social investment reforms are supported by individuals with higher levels of education, and by those who subscribe to economically leftwing 
and to more egalitarian social values. Neither individuals' income position, nor their gender, nor having small children are associated with support for social investment, which - together with the descriptive evidence displayed above - can be interpreted as indicating a broad base of support for social investment reforms. Surprisingly, we also find a strong and robust positive association between being retired and support for social investment policies. This is clearly at odds with conceptions of the elderly being opposed to welfare state reforms that mainly benefit the young (Busememyer et al. 2009). Yet, because this effect is limited to those in retirement, it might be that the transition from being a net taxpayer to becoming a welfare recipient leads to less concerns about taxes that need to be raised to finance social investment or that the elderly do in fact care about working conditions of younger generations and the provision of high-quality childcare for their grandchildren. In any case, this remains an interesting finding to be studied in future research.

Secondly, the characteristics of respondents supporting policy reforms expanding passive transfers are more reminiscent of the classic class-cleavage: We find strong negative effects of income, educational background, and male gender as well as a positive association for economically leftwing ideological orientation. Different from social investment, but in line with our expectation, supporters of passive transfers tend more towards the right on the social values dimension. Again, the effect of age on support is puzzling, since retired respondents oppose more generous passive transfers, but support is highest in the age group of those in their 50s. Analyses disaggregated by policy proposal, which we present in the Supplementary Material (Figure A.2), reveal that this effect is driven by the item of early retirement. Contrary to the proposal of pension increases (where we observe a positive linear effect of age), those in retirement would not benefit from more generous early retirement regulation. Furthermore, they 
might be concerned about negative side effects on the sustainability of pension payments. Support is highest among those that are close to reach the statutory retirement age.

Finally, support for "workfare" policies is concentrated among those with higher incomes (educational background seems to matter less in this case), who also tend towards more TAN-values and subscribe to an economically right-leaning position. This confirms that the characteristics of the group supporting workfare reforms - while also being smaller in size compared to social investment policies - are different, as it tends to be more concentrated in the "upscale" groups. Since labor market risk is partly correlated with income, these groups are less likely to experience unemployment spells themselves and therefore more supportive of reforms promoting stringent use of "their" taxes. This is also reflected by the effects of age: The reference group of those in their 30s are in their prime labor market age and probably find it relatively easy to change jobs and therefore are more in favor of workfare compared to the other age groups. 
Figure 2: Determinants of social investment, passive transfer, and workfare policy proposals.

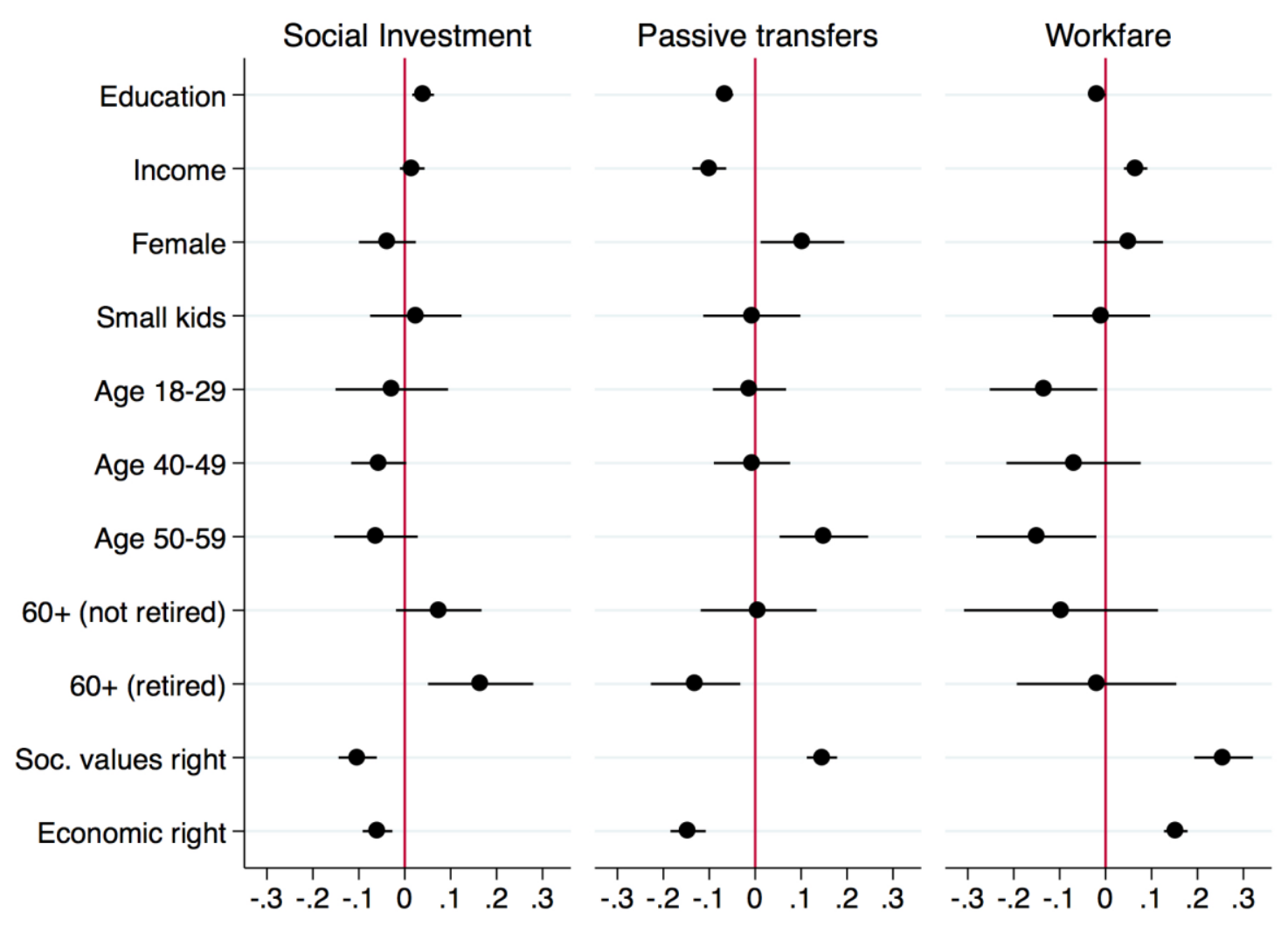

Note: Coefficients and 95\% confidence bands are plotted; OLS regressions, pooled sample, country fixed effects, robust country-clustered standard errors.

Summing up, our analysis reveals distinct differences in the patterns of support for different policy reforms, which could become the foundation for efforts of parties to mobilize political coalitions in support of their proposed policy packages: First, supporting the existing literature on compensatory social policies and redistribution more generally, we find that passive transfer policies are most supported by low-income and low-educated people and individuals leaning towards TAN-values, while also subscribing to left-wing economic attitudes. In contrast, we find that social investments are supported by individuals with a higher educational background and expressing left- 
libertarian views. This coalition is also relatively broad in terms of size and includes individuals from different socio-economic backgrounds (captured by income) and, surprisingly, also some pensioners. Finally, workfare policies are most popular with high-income individuals as well as those subscribing to economically conservative positions and traditional authoritarian values. In the Supplementary Material, we present and discuss a number of robustness tests, which demonstrate that the findings hold across model specifications and different variable operationalizations.

\section{Conclusion}

The debate about the social investment model remains a rather elite-centered discourse as most of the existing literature has focused on politics and policy-making on the macro-level. Our contribution expands this perspective by studying individual preferences. Using a new public opinion survey on social investment and welfare state policies, we found that peoples' welfare state preferences indeed cluster along three dimensions, related to social investment, passive transfers, and workfare policies. We found that social investments are by far the most popular policies across countries, and we identified different and distinct potential supporting groups for the individual policy 'packages'.

Our findings have important implications for the social investment debate: Contrasting the somewhat mixed assessments of the success of the social investment model on the level of policy-making (see de la Porte and Natali (2018) in this collection), our analysis shows that from citizens' perspective, social investment policies remain highly attractive. This is because they appeal both normatively as well as economically to large parts of the electorate. Put differently, contrary to social compensatory policies, social investments find support even among the high-skilled and richer individuals. But the 
analysis also revealed that the supporting coalitions for social investment reforms and more traditional social policies are distinct, hinting at potential trade-offs, political struggles, and conflicts over the transformation of existing welfare states. These struggles have already been apparent in the fate of social democratic parties in the last decades as they are torn between the interests of their erstwhile core electoral constituencies in the working classes and new left-libertarian constituencies in the welleducated middle classes (Beramendi et al. 2015; Kitschelt and Rehm 2015; Häusermann and Kriesi 2015). The same can increasingly be said about right-wing parties trying to appeal to the urban middle classes by expanding social services such as childcare. From the perspective of public opinion, there is considerable potential for centrist policies focusing on human skills and social investment. 


\section{Notes on contributors}

Julian L. Garritzmann is Senior Researcher at the University of Konstanz, Germany, and the University of Zurich, Zurich.

Marius R. Busemeyer is Professor of Political Science at the University of Konstanz.

Erik Neimanns is Senior Researcher at the University of Konstanz.

\section{Address for correspondence}

Marius R. Busemeyer, University of Konstanz, Postbox 79, Universitätsstrasse 10, 78457

Konstanz, Germany. Marius.Busemeyer@uni-konstanz.de

\section{Funding}

We gratefully acknowledge financial support by an ERC "Starting Grant", Grant No. 311769.

\section{Acknowledgments}

We wish to thank participants of the workshop "The Future of the Social Investment State", at the University of Lausanne, and at the CES conference in Glasgow, as well as the anonymous reviewers and the editors for helpful suggestions. 


\section{Endnotes}

${ }^{i}$ The ESS includes some questions on childcare and the ISSP Role of Government modules include a question on public education spending. But hitherto these surveys do not cover a broader range of social investment policies.

ii While the wording of some of the items is relatively complex, our pretests indicated that respondents understood the logic of the reform proposal sufficiently well. Thus they should provide valid measures. Most items mention several reform measures simultaneously. This has the drawback that respondents might value the individual components of the reform measures differently. But the question wording reflects our aim to present realistic reform proposals that are comparable across countries and avoid getting lost in specific reform details. The first and fourth item are replications from the Eurobarometer 56.1 (see e.g. Kananen et al. 2006).

iii If we treat responses on the five-point Likert scales as ordinal rather than continuous and use a polychoric correlation matrix as input for the principal component factor analysis (Welkenhuysen-Gybels et al. 2003), the findings remain unchanged.

iv Sweden also stands out because early retirement loads negatively on the "passive transfers"-dimension. We discuss the particularities of the issue of early retirement, which help to make sense of this outlying value, in more detail below.

v As an alternative, one could run multi-level/hierarchical random-effects models. These models yield the same coefficient estimates as the specification we use, but slightly larger standard errors. As the number of level-2 observations is relatively small $\left(\mathrm{N}_{\mathrm{j}}=8\right)$, we chose the common standard.

vi In Supplementary Material Figure A.1-A.2 and Table A.4, Models 4-9 we present additional models estimated separately for each policy proposal. 


\section{References}

Ansell, B.W. (2010) From the ballot to the blackboard: The redistributive political economy of education, New York: Cambridge University Press.

Barr, N. (2012) Economics of the Welfare State, Fifth Edition, Oxford, New York: Oxford University Press.

Bengtsson, M., de la Porte, C. and Jacobsson, K. (2017) 'Labour market policy under conditions of permanent austerity: Any sign of social investment?', Social Policy \& Administration 51(2): 367-388.

Beramendi, P., Häusermann, S., Kitschelt, H. and Kriesi, H. (2015) The Politics of Advanced Capitalism, Cambridge: Cambridge University Press.

Bonoli, G. (2007) 'Time matters: postindustrialization, new social risks, and welfare state adaptation in advanced industrial democracies', Comparative Political Studies 40(5):495-520.

Bonoli, G. (2010) 'The political economy of active labor-market policy', Politics and society 38(4):435-457.

Bonoli, G. (2013) The Origins of Active Social Policy: Labour Market and Childcare Policies in a Comparative Perspective, Oxford: Oxford University Press.

Bonoli, G. and Liechti, F. (2018) CONTRIBUTION IN THIS ISSUE. COPY EDITOR PLEASE ADD DETAILS.

Busemeyer, M.R. (2012) 'Inequality and the political economy of education: An analysis of individual preferences in OECD countries', Journal of European Social Policy 22(3):219-240.

Busemeyer, M.R., de la Porte, C., Garritzmann, J.L., and Pavolini, E. (2018) CONTRIBUTION IN THIS ISSUE. COPY EDITOR PLEASE ADD DETAILS. 
Busemeyer, M.R., Garritzmann, J.L., Neimanns, E. and Nezi, R. (2017) 'Investing in education in Europe: Evidence from a new survey of public opinion', Journal of European Social Policy DOI: 10.1177/0958928717700562

Busemeyer, M.R. and Garritzmann, J.L. (2017a) 'Academic, vocational, or general? An analysis of public opinion towards education policies with evidence from a new comparative survey', Journal of European Social Policy 27(4):373-386.

Busemeyer, M.R. and Garritzmann, J.L. (2017b) 'Public opinion on policy and budgetary trade-offs in European welfare states: Evidence from a new comparative Survey', Journal of European Public Policy 24(6):871-889.

Busemeyer, M.R., Goerres, A. and Weschle, S. (2009) 'Attitudes towards redistributive spending in an era of demographic ageing: the rival pressures from age and income in 14 OECD countries', Journal of European Social Policy 19(3):195-212.

Busemeyer, M.R., and Neimanns, E. (2017) 'Conflictive preferences towards social investments and transfers in mature welfare states: The cases of unemployment benefits and childcare provision', Journal of European Social Policy. DOI: https://doi.org/10.1177/0958928716684302.

de la Porte, C. and Natali, D. (2018) CONTRIBUTION IN THIS ISSUE. COPY EDITOR PLEASE ADD DETAILS.

Esping-Andersen, G. (2002) 'A child-centred social investment strategy', in G. EspingAndersen (ed.), Why we need a new welfare state, Oxford: Oxford University Press, pp. 26-65.

Fossati, F. and Häusermann, S. (2014) 'Social policy preferences and party choice in the 2011 Swiss elections',Swiss Political Science Review 20(4): 590-611. 
Garritzmann, J.L. (2015) 'Attitudes towards student support: How positive feedbackeffects prevent change in the Four Worlds of Student Finance', Journal of European Social Policy 25(2):139-158.

Garritzmann, J.L. (2016) The Political Economy of Higher Education Finance. The Politics of Tuition Fees and Subsidies in OECD Countries 1945-2015, Basingstoke: Palgrave Macmillan.

Garritzmann, J.L., Häusermann, S., Palier, B., and Zollinger, C. (2017) 'WoPSI - The World Politics of Social Investment: An International Research Project to Explain Variance in Social Investment Agendas and Social Investment Reforms across Countries and World Regions', LIEPP Working Paper: 64, SciencesPo, Paris.

Giddens, A. (1998) The Third Way: The Renewal of Social Democracy, New York: John Wiley \& Sons.

Goerres, A. and Tepe, M. (2010) 'Age-based self-interest, intergenerational solidarity and the welfare state: A comparative analysis of older people's attitudes towards public childcare in 12 OECD countries', European Journal of Political Research 49(6): 818-851.

Häusermann, S. (2018) CONTRIBUTION IN THIS ISSUE. COPY EDITOR PLEASE ADD

\section{DETAILS.}

Häusermann, S. and Kriesi, H. (2015) 'What Do Voters Want? Dimensions and Configurations in Individual-Level Preferences and Party Choice', in: P. Beramendi, S. Häusermann, H. Kitschelt, and H. Kriesi (Eds.) The Politics of Advanced Capitalism, Cambridge: Cambridge University Press, pp. 202-230. 
Häusermann, S., Kurer, T. and Schwander, H. (2015) 'High-Skilled Outsiders? Labor Market Vulnerability, Education and Welfare State Preferences', Socio-Economic Review 13(2): 235-58.

Hemerijck, A. (2013) Changing welfare states, Oxford: Oxford University Press.

Hemerijck, A. (2015) 'The Quiet Paradigm Revolution of Social Investment', Social Politics, 22(2):242-256.

Hemerijck, A. (2018) CONTRIBUTION IN THIS ISSUE. COPY EDITOR PLEASE ADD

\section{DETAILS.}

Henderson, T.L., Monroe, P.A., Garand, J.C. and Burts, D.C. (1995) 'Explaining Public Opinion towards Government Spending on Child Care', Family Relations 44(1): $37-45$.

Hooghe, L., Marks, G. and Wilson, C.J. (2002) 'Does Left/Right Structure Party Positions on European Integration?', Comparative Political Studies 35: 965-89.

Kananen, J., Taylor-Gooby, P. and Larsen, T.P. (2006) 'Public Attitudes and New Social Risk Reform', in: A., Klaus, and G. Bonoli (eds.), The Politics of Post-industrial Welfare States: Adapting Post-war Social Policies to New Social Risks, New York: Routledge, pp. 83-99.

King, D. (1995) Actively Seeking Work? The Politics of Unemployment and Welfare Policy in the United States and Great Britain, Chicago: University of Chicago Press.

Kitschelt, H. (1994) The Transformation of European Social Democracy, Cambridge: Cambridge University Press.

Kitschelt, H. and Rehm, P. (2015) 'Party Alignments: Change and Continuity', in: P. Beramendi, S. Häusermann, H. Kitschelt, and H. Kriesi (eds.) The Politics of Advanced Capitalism, Cambridge: Cambridge University Press, pp. 179-201. 
Mischke, M. (2014) Public Attitudes towards Family Policies in Europe. Linking Institutional Context and Public Opinion, Wiesbaden: Springer VS.

Morel, N., Palier, B. and Palme, J. (2012) Towards a social investment welfare state: Ideas, policies and challenges, Bristol: The Policy Press.

Pavolini, E. and Van Lancker, W. (2018) CONTRIBUTION IN THIS ISSUE. COPY EDITOR PLEASE ADD DETAILS.

Rueda, D. (2005) 'Insider-outsider politics in industrialized democracies: The challenge to social democratic parties', American Political Science Review 99(1): 61-74.

Welkenhuysen-Gybels, J., Billiet, J. and Cambré, B. (2003) 'Adjustment for acquiescence in the assessment of the construct equivalence of Likert-type score items', Journal of Cross-Cultural Psychology 34(6): 702-722.

Word count: $6508+$ one page of printed figures (2 figures) + one small table (63 words) $=7046$.

Supplemental data and material for this article can be accessed at [link to source publisher will add DOI at proof]. 